\title{
Review Article \\ Thyroid Functions and Bipolar Affective Disorder
}

\author{
Subho Chakrabarti \\ Department of Psychiatry, Postgraduate Institute of Medical Education and Research (PGIMER), Chandigarh 160012, India
}

Correspondence should be addressed to Subho Chakrabarti, subhochd@yahoo.com

Received 15 January 2011; Revised 23 April 2011; Accepted 29 May 2011

Academic Editor: Guillermo Juvenal

Copyright (C) 2011 Subho Chakrabarti. This is an open access article distributed under the Creative Commons Attribution License, which permits unrestricted use, distribution, and reproduction in any medium, provided the original work is properly cited.

\begin{abstract}
Accumulating evidence suggests that hypothalamo-pituitary-thyroid (HPT) axis dysfunction is relevant to the pathophysiology and clinical course of bipolar affective disorder. Hypothyroidism, either overt or more commonly subclinical, appears to the commonest abnormality found in bipolar disorder. The prevalence of thyroid dysfunction is also likely to be greater among patients with rapid cycling and other refractory forms of the disorder. Lithium-treatment has potent antithyroid effects and can induce hypothyroidism or exacerbate a preexisting hypothyroid state. Even minor perturbations of the HPT axis may affect the outcome of bipolar disorder, necessitating careful monitoring of thyroid functions of patients on treatment. Supplementation with high dose thyroxine can be considered in some patients with treatment-refractory bipolar disorder. Neurotransmitter, neuroimaging, and genetic studies have begun to provide clues, which could lead to an improved understanding of the thyroid-bipolar disorder connection, and more optimal ways of managing this potentially disabling condition.
\end{abstract}

\section{Introduction}

The association between thyroid functions and behavioural disturbances has been known for the last several hundred years. Although the effects of thyroid hormones on the developing brain were recognised long ago, recent advances in biotechnology have led to an improved understanding of the impact of thyroid functions on the adult, mature brain [1]. This development has been particularly helpful in elucidating the role of thyroid hormones in the pathophysiology of psychiatric disorders, especially mood disorders. The primary focus of interest has been on the connection between thyroid functions and depressive disorders. However, abnormalities of thyroid functions may also play an important role in the pathophysiology of bipolar affective disorder, but this area has received much less attention than it probably deserves.

This paper attempts to explore the links between thyroid hormone physiology and the presentation and pathogenesis of bipolar disorder. It briefly covers several areas of overlap, beginning with the association of bipolar disorders with thyroid disease among clinical and epidemiological populations, as well as the evidence of hypothalamo-pituitarythyroid (HPT) axis abnormalities among patients with bipolar disorder. Rapid cycling and other refractory forms of bipolar disorder have been particularly highlighted, since the prevalence of thyroid dysfunction appears to be greater in such forms of the disorder. The research relating to the widespread and potent antithyroid effects of lithium carbonate, the drug most commonly used for treating bipolar disorder, has been summarised next. The role of thyroid hormones in the treatment of bipolar disorder is also reviewed. Although the evidence supporting the use of adjunctive thyroid hormone treatment of bipolar disorder is somewhat meagre, such strategies may be useful in a subset of patients with chronic and refractory forms of bipolar disorder. Despite rapid strides made in uncovering cellular and molecular mechanisms of actions of thyroid hormones, the specific neurobiological processes that underlie the modulatory effect of thyroid hormones in mood disorders are far from clear. Animal studies have provided considerable data on the reciprocal interactions between thyroid hormones and neurotransmitter systems believed to play a role in genesis of mood disorders [2]. These studies provide the basis for several hypotheses (included in this paper), which propose that the modulatory effects of thyroid hormones on mood are mediated by their actions on different neurotransmitter systems. A brief mention has also been made of genetic and neuroimaging investigations that are beginning to attract considerable attention, since they can offer vital clues to the 
link between thyroid dysfunction and bipolar disorder. The paper ends with a discussion of the pertinent methodological issues and suggestions for future research, which can enhance our understanding of the thyroid-bipolar disorder link.

\section{The HPT Axis}

The organization and regulation of the HPT system has been extensively reviewed elsewhere [1-8]. Hence, only the relevant aspects are described here. The thyroid gland is the largest endocrine organ in the human body. The thyroid regulates cellular activity by releasing two different hormones, the prohormone thyroxine (T4) and the biologically active triiodothyronine (T3). The HPT system has a hierarchical structure similar to that of the hypothalamopituitary adrenal axis, with the thyrotropin-releasing hormone (TRH) as the hypothalamic master hormone. TRH is released from nerve endings in the median eminence; from here it enters the anterior pituitary through the portal system. In the pituitary, TRH induces synthesis and release of thyrotropin or the thyroid-stimulating hormone (TSH), from thyrotrophs. TSH enters the circulation and acts on the thyroid gland causing release of T3 and T4.

All T4 comes from the thyroid, but, under usual circumstances, only about $20 \%$ of T3 is derived from the gland. The remaining $80 \%$ comes from the removal of iodine from the T4 molecule by enzymes called deiodinases. Type-II deiodinase converts T4 to T3. This enzyme is located mostly in glial cells of various regions of the brain, principally the cortical areas and the anterior pituitary. The activity of type II deiodinase is primarily responsible for regulating brain T3 concentrations. The actions of thyroid hormones at the cellular level are initiated by the intracellular binding of T3 to nuclear thyroid hormone receptors. These receptors are widely distributed in the adult brain, with higher densities in phylogenetically younger brain regions (e.g., amygdala and hippocampus), and lower densities in the brain stem and cerebellum. The entry of T3 into the cell is mediated by two plasma membrane carriers, the monocarboxylate transporter and the organic anion-transporting polypeptide. After the coupling of T3 to nuclear receptors, the transcriptionally active complex binds to thyroid hormoneresponsive elements located on thyroid hormone-responsive genes. This binding produces conformational changes in thyroid hormone responsive genes, which initiates a sequence of transcription of messenger ribonucleic acid, increased gene expression, and synthesis of proteins. Although the mechanisms of thyroid hormone effects on the brain are not fully known, they probably include genomic actions, an effect on neurotransmission directly at the synapse, and modulation of neurotransmitter systems and intracellular signalling pathways.

The HPT axis is regulated by several complex feedback mechanisms at all levels. Unbound or free T3 and T4 feed back at the level of the hypothalamus to inhibit TRH release, and at the anterior pituitary level to inhibit TSH release. Different neurotransmitters and hormones either promote or inhibit release of TRH and TSH. The HPT axis is also regulated by stress-responsive elements, which influence
TRH levels, and by the circadian system's influence on TSH. At the level of brain, additional mechanisms such as circulating levels of T3 and T4, intracellular transport, and deiodinase activity regulate local concentrations of thyroid hormones. Consequently, levels of T3 within the brain are tightly controlled within narrow limits, even under adverse conditions [1-8].

\section{Thyroid Disease and Bipolar Disorder}

Neuropsychiatric symptoms, such as mood disturbances and cognitive impairment, are very common among patients with thyroid disorders.

Hyperthyroidism or thyrotoxicosis is usually associated with symptoms such as anxiety, depression, mood lability, and insomnia in a majority of the patients. However, overt psychiatric disorder is rare and occurs in only about $10 \%$ of the patients $[1,5]$. Manic episodes have been known to occur in patients with hyperthyroidism, but are quite unusual [9]. Occasionally, patients with late-onset mania are detected to have hyperthyroidism, which requires to be treated to achieve full recovery [10]. Nevertheless, patients who develop a true manic episode while thyrotoxic, frequently have an underlying mood disorder, or a family history of mood disorder $[11,12]$. Manic episodes can also result from the relatively uncommon phenomenon of lithium carbonateassociated thyrotoxicosis $[9,13]$. Lithium may induce thyrotoxicosis by several mechanisms including triggering of the autoimmune process with resultant thyroiditis, abnormal iodine kinetics, that is, overflow of thyroid hormone after expansion of the intrathyroid iodine pool, Jod-Basedow-like phenomenon, direct toxicity to thyroid follicles resulting in release of thyroglobulin, and coincidental Graves' disease and hyperthyroidism [14-16].

Psychiatric symptoms in hyperthyroidism, such as anxiety or mania, appear to be mediated by beta-adrenergic hyperactivity. Accordingly, psychiatric symptoms and psychiatric disorders secondary to hyperthyroidism should be first treated by restoring the euthyroid state. Additional treatment with beta-adrenergic antagonists is also helpful. Antimanic agents are required only when symptoms fail to respond to these measures [8].

The most common psychiatric symptoms related to hypothyroidism are depression and cognitive dysfunction $[1,3,8]$. Only a few instances of mania or hypomania associated with hypothyroidism have been reported in the literature [17]. Underlying mechanisms are less clear; they could include dysregulation of CNS catecholamine receptor sensitivity, associated thyroditis and thyrotoxicosis, or a disruption of circadian rhythms [18]. A retrospective review based on 18 patients described an organic affective syndrome-manic type occurring shortly after the initiation of thyroid replacement in hypothyroid patients [19]. Patients experiencing mania were predominantly female, often had concurrent psychotic symptoms, frequently had a personal or familial history of psychiatric disorder, and had received more than $150 \mathrm{mcg} /$ day of thyroxine. The authors suggested that rapid administration of thyroxine could abruptly augment catecholamine receptor sensitivity, thereby 
precipitating a hypercatecholaminergic state and subsequent manic symptoms. Similar instances of T3-induced mania in patients with bipolar depression have also been reported [20]. It has been speculated that thyroid hormonecatecholamine receptor interactions might underlie these T3-associated clinical manifestations as well [20].

Even though thyroid disorders are associated with psychiatric symptoms in clinical populations, existence of a similar association in general population is less certain. On one hand, are the reports of a positive association between thyroid disease and mood disorders in some community studies. For example, a group of investigators at Copenhagen conducted prospective cohort studies utilising historical data from Danish case registers to determine the association between thyroid and affective disorders [21-23]. In separate reports, it was demonstrated that patients hospitalised with bipolar disorder tended to be at a greater risk of readmission with hyperthyroidism than controls [21], while patients hospitalised with hyperthyroidism were at greater risk of readmission with depressive disorder or bipolar disorder than controls [22]. Finally, patients hospitalized with hypothyroidism also had a greater risk of readmission with depression or bipolar disorder, than control patients [23]. These reports thus provided strong epidemiological support for a link between thyroid disease and mood disorders, including bipolar disorder. Further evidence for this association came from two other studies. The first such study was based on analysis of a series of insurance claims for inpatient hospitalisation, physician office visits, and laboratory testing [24]. These data were used to estimate the risk of having a comorbid condition among patients with bipolar disorder. In this study, the risk of hypothyroidism among bipolar patients was twice that of those with no mental health disorders. Another multicentric study from France included 1090 patients with bipolar I disorder, 9\% of whom had rapid cycling bipolar disorder (RCBD). Examination of comorbid medical conditions revealed that among the various physical disorders, only thyroid disorders were associated with rapid cycling [25]. On the other hand, quite a few other investigations of medical comorbidity among patients with bipolar disorder have not found a significant increase in the prevalence of thyroid disorders [26-28].

In conclusion, even though both hyperthyroidism and hypothyroidism are associated with changes in mood, overt bipolar disorder is uncommon in thyroid dysfunction. Moreover, data from community-based samples, in contrast to clinical samples, provide conflicting results regarding the association between thyroid diseases and bipolar disorder.

\section{HPT Axis Dysfunction in Bipolar Disorder}

Although HPT axis dysfunction appears to be equally relevant for the pathophysiology of bipolar disorder, as it is for depressive disorders, this subject has received far less attention from researchers. However, there is now growing evidence of all manner of thyroid abnormalities in patients with bipolar disorder, which often far exceed those found among patients with unipolar depression $[1,3,5,29,30]$. As discussed subsequently, thyroid dysfunction is particularly common in patients with the rapid cycling variant of bipolar disorder. However, the antithyroid action of moodstabilisers, particularly lithium carbonate, frequently confounds the findings among patients with bipolar disorder. Accordingly, there is some uncertainty about the true extent of HPT abnormalities in bipolar disorder and the proportion of HPT dysfunction that can be attributed to lithiumtreatment $[1,5,29]$.

Overt hyperthyroidism is uncommon in bipolar disorder; its prevalence is no greater than $2 \%$ across different studies [13, 15, 31]. Much of this has been attributed to lithium [32], which can induce thyrotoxicosis by autoimmune mechanisms or thyroiditis [14-16]. A transient elevation of T4 or free T4 levels has often been noted among patients with mania shortly after hospitalization [33-36]. These levels gradually normalize after a few weeks of treatment, as patients achieve remission. There is some suggestion that elevated T4 levels following hospitalisation are positively associated with severity of symptoms, and that the rate of fall in these levels is linked to a better outcome $[34,36,37]$. However, this finding is not specific to mania, as transient mild elevations of free and total T4 ("euthyroid hyperthyroxinemia") have been commonly noted in acutely admitted psychiatric patients, including those with depression. This indicates that such elevations are more likely to be nonspecific effects of the stress of hospitalisation [3, 38]. Currently, the most diagnostically sensitive tests to detect thyroid dysfunction are the ultrasensitive immunoradiometric assays of serum TSH [39]. However, prior to the development of highly specific and sensitive TSH assays, the TSH response to an intravenous dose of TSH was the most widely used test for detecting HPT dysfunction. The response is exaggerated in hypothyroidism and blunted in hyperthyroidism. A blunted TSH response occurs in $25-30 \%$ of patients with unipolar major depression [40]. However, blunted TSH responses to TRH may be far more common among patients with bipolar disorder, including those with mania [41, 42], bipolar depression $[43,44]$, and rapid cycling disorder [45]. Moreover, the severity of mood symptoms and milder fluctuations in these symptoms has been found to correlate with blunted TSH responses to TRH [46]. On the other hand, many patients with bipolar disorder may show an exaggerated response of TSH to TRH [47]. This is often associated with elevated basal serum TSH levels; approximately $20 \%$ of the patients have levels above the upper normal reference range [48, 49]. Exaggerated TSH responses, along with elevated basal levels of TSH, have also been noted among patients with rapid cycling and are consistent with the high prevalence of subclinical hypothyroidism often found in this condition $[3,29]$. Gyulai et al. [50] found that patients with RCBD did not differ from controls on any of thyroid function tests prior to treatment with lithium. However, after 4 weeks of lithium-treatment, exaggerated TSH responses to TRH were significantly more common among such patients. They, thus, proposed that RCBD is associated with a latent hypofunction of the HPT system, which becomes manifest with lithium treatment. Given lithium's antithyroid actions, it is not surprising that an exaggerated TSH response 
to TRH stimulation is extremely common and has been reported in $50-100 \%$ of lithium-treated patients [51]. Then again, evidence of overt or subclinical hypothyroidism, including raised antibody titres, has often been found among patients with bipolar disorder, prior to treatment with lithium $[31,52,53]$. Accordingly, it appears that, at least in a subgroup of patients with bipolar disorder, treatment with lithium, rather than inducing hypothyroidism, actually exacerbates a preexisting (overt) HPT dysfunction [32].

In summary, HPT axis abnormalities are quite common among patients with bipolar disorder. However, there are several concerns regarding the specificity of these abnormalities, and the effect of lithium in inducing HPT dysfunction in bipolar disorder.

\section{HPT Axis Dysfunction in Rapid Cycling Bipolar Disorder and Mixed Affective States}

Rapid cycling usually affects about 9 to $20 \%$ of all patients with bipolar disorder [25, 54-56]. This subpopulation is characterized by more severe morbidity and a refractory clinical course. More women, than men, suffer from rapid cycling $[54,55]$.

Of all the potential risk factors for rapid cycling, hypothyroidism has received the most attention. All categories of HPT axis dysfunctions have been reported in RCBD. These have included overt hypothyroidism [29, 57-59], elevated TSH levels [58, 60-62], exaggerated TSH responses to TRH [62], elevated antibody titres [63], and antidepressantinduced rapid cycling $[41,58]$. However, methodological problems such as retrospective designs, lack of controls, predominance of female subjects, and varying definitions of hypothyroidism have all hindered any consistent conclusions from these data [50]. Moreover, a number of other studies have been unable to document this association $[45,52$, 53, 64-68], promoting considerable scepticism about the presence of HPT axis abnormalities in RCBD [54, 55, 68, 69]. More pertinently, many of the studies reporting a positive association have included patients being treated with lithium. Lithium treatment clearly contributes to the development of hypothyroidism among patients with rapid cycling $[50,70]$. In this regard, the study by Gyulai et al. [50] is of some significance. Their contention that RCBD is associated with a latent hypofunction of the HPT system, which becomes manifest with short-term lithium challenge, remains a possibility. (The wide ranging anti-thyroid effects of lithium are described in the next section.) A latent hypofunction of the thyroid axis in RCBD may also explain why high doses of T4 added to the established treatment with lithium and other psychotropic drugs can reverse the rapid cycling pattern $[1,5]$.

Mixed affective states have also been associated with reduced thyroid functioning in certain studies. In a study of first-episode manic and mixed types of bipolar disorder, 33\% of the patients in mixed episodes had elevated TSH levels, in comparison with $7 \%$ of patients experiencing pure mania [71]. In similar vein, Chang et al. [72] found significantly lower T4 levels and elevated TSH levels in patients with mixed mania, compared with those with pure mania. These differences were not associated with exposure to lithium. Others have reported that patients with mixed states have a higher rate of positive anti-thyroid antibody titres, than other unipolar or bipolar subgroups, apparently unrelated to lithium treatment $[73,74]$. However, not all studies have been able to confirm the association of overt or subclinical thyroid dysfunction with mixed manic episodes $[75,76]$. Thus, the question of HPT dysfunction in mixed affective states remains an unresolved one [69].

To conclude, the prevalence of HPT dysfunction is very high among patients with RCBD. Despite concerns about methodology, contrary findings and confounding effects of lithium-treatment, the existence of a latent thyroid dysfunction in RCBD, which is exacerbated by lithium, remains a possibility. In contrast, the evidence linking HPT dysfunction and mixed affective states is inadequate and inconsistent.

\section{Lithium and HPT Axis Dysfunction}

The anti-thyroid effects of lithium carbonate are well documented $[51,77,78]$. The mechanisms by which lithium can cause hypothyroidism are complex. Lithium is concentrated by the thyroid gland and inhibits thyroidal iodine uptake. It also inhibits iodotyrosine coupling, alters thyroglobulin structure, inhibits thyroid hormone secretion [51], and interferes with the deiodination of $\mathrm{T} 4$ to $\mathrm{T} 3$ by inhibiting type-II deiodinase in the brain [79]. Lithium may evoke an exaggerated TSH response to TRH [51]. The drug may have an immunostimulant effect, either by inducing, or by exacerbating a preexisting autoimmune disease $[32,80]$. Additionally, lithium alters cellular responsiveness to thyroxine, and influences thyroid hormone receptor gene expression [81]. Inhibition of thyroid hormone release, a process mediated by cyclic adenosine monophosphate, appears to be the critical mechanism in the development of lithium-induced hypothyroidism [32]. Compensatory mechanisms may operate to prevent the development of hypothyroidism or goitre in the majority of patients with lithium-induced impairments in thyroxine secretion. However, when additional risk factors such as iodine deficiency, preexisting autoimmunity, or genetic vulnerability are present, such compensatory mechanisms fail and hypothyroidism eventually ensues [32].

Rates of overt hypothyroidism vary from 0 to $47 \%$ (average of about $10 \%$ ) among patients on long-term treatment with lithium $[32,80,82,83]$. Differences in study design, definitions of hypothyroidism, age, gender, and geographical origin of patients, are often responsible for such wide variations in rates. Nevertheless, both the incidence and prevalence of overt hypothyroidism is significantly higher among patients on lithium, compared to general population figures [32]. The average duration of lithium therapy before the diagnosis of hypothyroidism is around 18 months [83], though there are a few reports of hypothyroidism occurring within the first few months of lithium-treatment $[84,85]$. Female gender, middle age ( $>50$ years), preexisting autoimmunity, and family history of thyroid diseases are established 
risk factors for lithium-induced hypothyroidism $[82,83,86$, 87]. An even larger number of patients appear to develop subclinical hypothyroidism. Low or normal T4 levels and elevated TSH levels are reported among 5 to $35 \%$ (average of about 25\%) patients on lithium [88], while exaggerated TSH responses are found among 50\%, or more, of such patients $[51,89]$. Cross-sectional studies of lithium-induced goitre reveal a prevalence of 0 to $60 \%$ [51]; prevalence estimates are much higher (30-59\%) when more sensitive ultrasonographic scans are used to detect increases in thyroid volumes [32, 87, 90]. Several studies of patients on lithium have found an elevated rate of anti-thyroid antibodies, ranging from about 8 to $49 \%$ in such patients; these rates were significantly higher than those among control patients or the general population $[84,89,91-100]$. An almost equal number of studies have failed to find an association between elevated antibody titres and exposure to lithium $[32,53,73$, $74,101-104]$. Studies are similarly inconsistent as to whether thyroid antibodies are elevated in bipolar disorder, unrelated to lithium-treatment; reported rates range from 0 to $43 \%$ among patients with bipolar disorder not on lithium. Some controlled comparisons have reported a higher prevalence of thyroid antibodies in bipolar disorder [73, 74, 105], especially in depressed and mixed states [73, 74], and RCBD [63]. In the largest study of this kind, Kupka et al. [53] found thyroperoxidase antibodies in 64 of $226(28 \%)$ outpatients with bipolar disorder, a rate higher than general population subjects and patients with other psychiatric disorders. The presence of anti-thyroid antibodies among patients with bipolar disorder was associated with thyroid failure, but not with age, gender, mood state, rapid cycling, or lithium exposure [53]. However, several other controlled studies have not been able to find a higher prevalence of raised antibody tires in bipolar disorder, unrelated to lithium treatment $[64,103,106]$.

To summarise, anti-thyroid actions of lithium are diverse and complex. Rates of overt and subclinical hypothyroidism, goitre, and raised antibody titres all appear to be significantly higher among patients on lithium, compared to the general population and nonbipolar controls. However, prospective studies have shown that elevated rates of thyroid hypofunction continue to decline with continued lithium treatment. Consequently, the prevalence of lithium-induced hypothyroidism begins to approximate rates among general population, after several years of lithium treatment, even in the absence of thyroid supplementation $[32,88]$. The development of hypothyroidism is, thus, not a contraindication to continuing lithium. Thyroxine supplementation is recommended instead, even though there is considerable disagreement about when T4 should be added. Nevertheless, overt hypothyroidism, significantly enlarged thyroid volumes, clear evidence of subclinical pathology, and the presence of rapid cycling or treatment-resistance are unequivocal indications for T4 supplementation. Baseline tests of thyroid functions and size, and similar annual examinations are essential for all patients on lithium. Closer monitoring is recommended when risk factors such as female gender, middle age, autoimmunity, or positive family history are present $[3,32,88,107,108]$.

\section{HPT Axis Dysfunction and Outcome of Bipolar Disorder}

Regardless of the controversies about the nature and extent of HPT axis dysfunction in bipolar disorder, there is substantial evidence that even minor perturbations of thyroid function play a significant role in the clinical course, treatment response, and outcome of bipolar disorder. For example, studies have shown that among patients with bipolar depression, a relatively elevated free $\mathrm{T} 4$ index in men was associated with a faster response to antidepressants and a shorter length of hospital-stay [109], while lower free T4 values and higher TSH values were significantly associated with a poorer response during the initial phase of treatment [110]. A similar relationship between T3 and T4 levels and short-term outcome of mania has also been demonstrated [33, 36]. Moreover, the long-term efficacy of lithium prophylaxis also seems to be determined by alterations in the HPT axis. Higher T3 levels were found to predict better response to lithium, and lesser likelihood of depressive recurrences during the first few years of lithium treatment in a couple of studies $[111,112]$. Additionally, Frye et al. [85] reported that a lower mean serum level of free T4 was associated with more affective episodes and greater severity of depression during the first year of lithium-treatment. More recently, a retrospective analysis has shown that lithium-treated subjects who required an intervention for a depressive episode had significantly increased mean TSH levels, in comparison to lithium-treated subjects who did not require any intervention for depression [113].

In conclusion, several HPT axis abnormalities, which may have an important bearing on outcome, have been documented during acute-phase treatment of bipolar disorder. Similar findings during maintenance-phase treatment with lithium are consistent with the well-known anti-thyroid effects of lithium. Therefore, lithium-induced changes in thyroid function, even within the normal range, are detrimental to its prophylactic efficacy, especially with regard to depressive symptoms $[85,110,113]$. The presence of HPT dysfunction during lithium-treatment further underlines the need for regular monitoring of thyroid functions and rapid correction of any abnormalities that arise during such treatment. It may also explain why T4 supplementation can enhance treatment-response in some patients with refractory mood disorders on lithium treatment.

\section{Thyroid Hormone Supplementation in Bipolar Disorders}

The use of synthetic thyroid hormones T3 and T4 as supplementary agents in affective illness has a long history, with the first reports appearing in the late 1960s [1, 48]. However, the bulk of the studies have been carried out among patients with depression, where mostly T3, and occasionally T4, have been used to accelerate or augment antidepressant treatment. Among patients with bipolar disorder, supraphysiological doses of T4 have been used to supplement prophylactic efficacy of mood stabilizing treatments and 
to augment antidepressant treatment in patients with treatment-refractory bipolar depression.

Stancer and Persad [114] were the first to report the effects of supraphysiological doses of T4 used as the sole prophylactic agent in RCBD. Such treatment was only partially successful, with cessation of cycling in five of the eight women included in their study, but not in the two men. This study was followed by case reports which suggested that addition of supraphysiological doses of T4 to mood stabilizing treatments was more likely to prevent rapid cycling [115]. Bauer and Whybrow [116] conducted the first open-label trial of adjunctive supraphysiological doses of T4 in 11 patients with treatment-refractory RCBD. Adjunctive treatment with T4 reduced the severity of manic and the depressive phases in both amplitude and frequency, and even led to complete remission in some patients. Of the four patients who subsequently underwent singleor double-blind placebo substitution, three relapsed. In responders, supranormal circulating levels of free thyroxine were necessary to induce a clinical response. Side effects were minimal, and there were no signs or symptoms of thyrotoxicosis. Subsequently, other open-label studies found adjunctive treatment with supraphysiological doses of L-T4 to be effective in the maintenance treatment of patients with severe rapid cycling or resistant bipolar disorder, who did not respond to standard measures [117, 118]. Thyroxine was used in doses of $250-500 \mathrm{mcg} /$ day in these studies; the goal was to achieve TSH suppression by increasing free T4 levels by $\geq 50 \%$ of pretreatment levels. Despite concerns about adverse effects, the treatment was rated favourably by recipients and was well tolerated [119]. There was little evidence of cardiovascular side effects [116]. Moreover, the risk of bone demineralisation was not increased among women, even after several years of treatment [120-122].

In a separate set of open trials, supraphysiological doses of T4 were used to augment antidepressant treatment among treatment-resistant patients with bipolar depression [122124]. Augmentation of antidepressants with high dose T4 had a beneficial effect on depressive symptoms in this group of refractory patients as well. The treatment was well tolerated, the rise in T3 and T4 levels was minimal, and no complications were reported $[124,125]$. This pattern of response was significantly different from healthy controls administered thyroxine [125]. Two of the more recent studies have attempted thyroid hormone augmentation of patients with refractory bipolar depression using slightly different strategies. Łojko et al. [126] found addition of moderate doses of T4 (100 mcg/day) to be a successful augmentation strategy in female patients with bipolar depression, who had had an unsatisfactory response to serotonergic antidepressants. Another retrospective chart review of 125 patients with treatment-resistant bipolar depression showed augmentation with high dose T3 to be highly effective, though there were some concerns about adverse effects of this treatment [127].

The mechanisms underlying successful treatment with adjunctive T4 are as yet unclear. Earlier, it was suggested that adjunctive T4 counteracts the effects of subclinical hypothyroidism on neuronal adaptation $[4,5]$. However, contrary to this notion, most patients who responded had normal thyroid functions [123]. This has led to several alternative hypotheses, such as correction of peripheral resistance to thyroid hormones, correction of isolated CNS hypothyroidism, and positive modulation of cathecholaminergic systems by T4, being responsible for this beneficial effect [123].

To summarise, there is some evidence favouring the usefulness of T4 supplementation of mood stabilising treatments in a subset of patients with chronic and refractory forms of bipolar disorder. However, such evidence is still meagre. There are no randomised controlled trials, and the total number of patients included in existing studies is too small. Therefore, this strategy can only be considered as a treatment of last resort in patients who have failed to respond to all other measures.

When augmentation is attempted, thyroxine is usually started at $50-100 \mathrm{mcg} / \mathrm{day}$ and increased by $25-50 \mathrm{mcg}$ per week, to a maximum of $500 \mathrm{mcg}$ per day. Response to treatment is usually evident within the first 2 weeks. Treatment is continued in responders for a few months. In nonresponders, T4 is tapered off gradually, since abrupt discontinuation can result in iatrogenic hypothyroidism. Most side effects can be avoided to a great extent by gradually building up the dose, adjusting it carefully, and monitoring the patient closely. Special precautions are required in those with endocrine or cardiovascular disorders. Administration during pregnancy is not recommended. A careful lookout should also be kept for the drugs being abused for their weight reduction effects $[1,3-5,8]$.

\section{HPT Axis Dysfunction and Bipolar Disorder: Underlying Neurobiological Mechanisms}

The mechanisms, by which thyroid dysfunction produces mood symptoms, as well as those involved in amelioration of mood symptoms by thyroid hormones, remain to be more fully elaborated and understood. However, studies involving neurotransmitter functions, genetics, and neuroimaging have uncovered some of the cellular and molecular processes, which may explain the link between HPT axis dysfunction and mood disorders.

9.1. Neurotransmitter Systems. The role of several neurotransmitter systems including norepinephrine (NE), serotonin(5-HT), dopamine (DA), and gamma aminobutyric acid (GABA) in the pathogenesis of mood disorders is now reasonably well established [128-130]. Interactions between thyroid hormones and these neurotransmitter systems may not only account for the psychiatric symptoms accompanying thyroid disease, but also for the HPT dysfunction in mood disorders, and the therapeutic actions of thyroid hormones in mood disorders $[1,2,5,48,49]$. There are several similarities between the HPT and neurotransmitter systems, which endorse the possibility of mutual interactions. Firstly, because of their common biosynthetic precursor tyrosine, thyroid hormones (especially T3) are structurally similar to NE and DA [131]. Moreover, both systems are present in 
key brain regions. Thyroid hormone receptors are widely distributed in the brain; many of the limbic system structures where these receptors are present have been implicated in the pathogenesis of mood disorders. The neurotransmitter systems originate in the brainstem and extend through the midbrain into the limbic regions and the cortex. They regulate mood by modulating the activity of these brain areas $[2,5]$. Finally, components of both systems appear to coexist at the tissue level. Immunohistochemical mapping studies have shown that T3 is concentrated in the nuclei and projection sites of central noradrenergic systems [132], while the thyroid gland exhibits GABA transport mechanisms, as well as enzyme activities for GABA synthesis and degradation [133]. This suggests that thyroid hormones could act as neurotransmitters and neuromodulators by themselves; alternatively, their mood-regulatory properties could be mediated by interactions with the principal neurotransmitter systems.

The interactions between thyroid and neurotransmitter systems are often complex and reciprocal. Effects of neurotransmitter systems on TRH and TSH are better characterised. NE stimulates both TRH and TSH release, while 5-HT, DA, and GABA inhibit their release $[134,135]$. On the other hand, evidence about the effect of thyroid hormones on neurotransmitters is mostly derived from animal studies. Such evidence principally consists of altered responsiveness of NE, 5-HT, DA, and GABA systems in the adult/mature brain, resulting from experimentally induced hypothyroid or hyperthyroid states [2, 5, 133, 136, 137]. In addition, thyroid hormones also appear to have important effects on intracellular signal transduction mechanisms, such as $\mathrm{G}$ proteins, adenylate cyclase, and phosphoinositide-based signalling pathways in the adult brain $[2,5]$. Apart from these interactions in the mature brain, thyroid-neurotransmitter interactions also play a significant role in the developing brain. Indeed, the actions of thyroid hormones on neurotransmitter systems appear to be more pronounced in neonatal animals $[2,138]$, thus, underlining the important effects of thyroid hormones on formation and organization of neurotransmitter systems in the developing brain [139-141].

The hypothesis that interactions between thyroid and neurotransmitter systems may have a causal role in the pathophysiology of mood disorders was originally proposed by Whybrow and Prange [142]. They suggested that the antidepressant properties of T3 could be explained by its augmentation of postsynaptic beta-adrenergic activity. Hypothyroidism was, thus, believed to cause depression by producing a functional decrease in noradrenergic transmission. The obverse of this would be mania caused by a hyperadrenergic state. The reports of mania following rapid administration of thyroid hormones described earlier $[19,20]$ seem to support this possibility. The noradrenergic hypothesis has since been modified to include the modulating influence of thyroid hormones on other neurotransmitters. Research data, primarily from animal studies, indicate similar effects of thyroid hormones on the serotonin system. Augmentation of serotonergic transmission by thyroid hormones results from a combination of a reduction of the sensitivity of 5-HT 1A autoreceptors in the raphe nuclei and an increase in 5-HT 2 receptor density and sensitivity in the cortex [2]. Additionally, neuroendocrine challenge studies in hypothyroid patients have shown reduced 5-HT responsiveness, which is reversible with thyroid replacement therapy [2, 137]. Abnormalities of the 5-HT systems have also occasionally been found among patients with depression with documented HPT axis dysfunction [2, 137]. This has led to the speculation that the serotonin system may be involved in the mood-modulating effects of thyroid hormones among patients with mood disorders [2], and that serotonin deficiency could account for several of the HPT axis abnormalities observed in depression [48]. On similar lines, it has also been suggested that disorders of dopaminergic and GABAergic neurotransmission could account for the psychiatric manifestations of thyroid dysfunction [137, 140], but, the evidence for such suppositions is insufficient. Moreover, it is apparent that much of the evidence on thyroid-neurotransmitter interactions is currently based on animal studies. Studies among humans are scarce [137]; the few that have involved patients with mood disorders have been limited to those with depression [2]. Thus, though thyroid-neurotransmitter interactions seem to play a role in the pathogenesis and treatment of mood disorders, the specific interactions underlying modulatory effects of thyroid hormones among patients with bipolar disorder, are yet to be clearly elucidated.

9.2. Neuroimaging Investigations. Newer findings from neuroimaging studies have suggested that HPT axis dysfunction may be more fundamentally related to the aetiopathogenesis of bipolar disorder. In a PET study of hypothyroid patients undergoing thyroid hormone replacement, reduction of the behavioural complaints during therapy was associated with a restoration of metabolic activity in brain areas that were integral to the regulation of affect and cognition [143]. Similarly, in another PET study of untreated Graves' disease, thyrotoxicosis and attendant psychological symptoms were associated with regional metabolic changes of limbic structures that mediate affect [144]. These findings have been complemented by neuroimaging investigations of patients with bipolar disorder. In a seminal PET study of medication-free, treatment-resistant patients with primarily RCBD, serum TSH levels were inversely related to both global and regional cerebral blood flow, and cerebral glucose metabolism [145]. These results suggested that relationships between thyroid and cerebral activity could not only explain HPT axis contributions to the genesis of bipolar disorders, but, could also account for the therapeutic effects of thyroid hormones in bipolar disorders. In another study, ten women with bipolar depression underwent PET, before and after seven weeks of adjunctive treatment with supraphysiological doses of L-T4 [123]. The authors found that patients with bipolar depression had abnormal uptake in prefrontal and limbic brain areas, in structures integral to affect regulation, which have been specifically implicated in bipolar disorder. Administration of thyroxine appeared to improve mood by affecting circuits involving the very same areas. The role of autoimmunity in development of cerebral perfusion abnormalities in patients with thyroid disease is still 
unclear. However, SPECT studies of asymptomatic, euthyroid patients with autoimmune (Hashimoto's) thyroiditis had earlier revealed a high prevalence of mild brain perfusion abnormalities [146, 147]. More recently, cortical perfusion asymmetry (particularly between frontal lobes) was found in a SPECT study of a patient with bipolar disorder and Hashimoto's thyroiditis, leading the authors to hypothesize that abnormalities in cortical blood flow might represent a pathogenic link between thyroid autoimmunity and bipolar disorders [148].

9.3. Genetic Investigations. One of the key recent developments in this area has been the research evidence suggesting that HPT abnormalities may be a potential endophenotypes for bipolar disorder. Vonk et al. [149] compared the prevalence of thyroperoxidase antibodies among 22 monozygotic twins and 29 dizygotic twins with bipolar disorder, with 35 healthy control twins. Antibody titres were positive in $27 \%$ of the twins with bipolar disorder, compared to only $16 \%$ in healthy control twins. The authors proposed that autoimmune thyroiditis (with raised antibody titres as markers) could be an endophenotype for bipolar disorder and could be related to the genetic vulnerability to develop bipolar disorder. In another study, a significantly higher prevalence of thyroperoxidase antibody titres was predominantly found in daughters of parents with bipolar disorder, compared to the female high school and young adult comparisons [150]. Therefore, children of parents with bipolar disorder were found to be more vulnerable to develop thyroid autoimmunity, independently of their vulnerability to develop psychiatric disorders. Coincidentally, recent studies have found HPT abnormalities among children with severe affective, behavioural, and cognitive impairments, who could be a part of the broad behavioural phenotype of bipolar disorder [151].

Additionally, a few recent studies utilising genetic variant analysis have also attempted to elucidate elements of HPT axis dysfunction underlying thyroid-mood disorder interactions [7]. For example, in a case-control association study of Chinese patients, genetic variations of the type II deiodinase gene were associated with bipolar disorder [152]. Moreover, animal studies have shown that genetic mechanisms are involved in regulation of striatal physiology by T3; this could explain the beneficial effects of thyroid hormones in mood disorders [153]. Genetic mechanisms have also been invoked to explain lithium-induced hypothyroidism [154]. Although the research is still at a preliminary stage, these findings suggest that genetic investigations are more likely to eventually unravel the link between thyroid dysfunction and bipolar disorder.

\section{Methodological Issues}

Despite the impressive advances made in research on HPT axis dysfunction in abnormal mood states, including bipolar disorder, there are quite a few methodological hurdles that are yet to be overcome. One of the principal areas of concern relates to the variability and inconsistency of the nature of HPT axis abnormalities documented among patients with these disorders. Much of this stems from inadequate sample sizes, diagnostic heterogeneity, lack of proper controls for confounding factors, and improper standardization of thyroid function tests [5]. Moreover, given the unique organization of brain thyroid systems, peripheral measures of thyroid function may not adequately characterise central thyroid metabolism [1]. A clearer understanding of the role of HPT axis dysfunction in bipolar disorder is unlikely to emerge if these aspects of study-designs are not addressed. Additionally, the bulk of research on neurobiological mechanisms underlying the thyroid-mood disorder link has been conducted among animals. Studies among mood disordered subjects are very few and limited to those with depression. The methods employed to assess CNS neurotransmitter function have also varied considerably. Therefore, more methodologically sound studies among clinical subjects are required to assess potential interactions between these neurochemical systems in the CNS and thyroid functions $[2,137]$.

\section{Conclusions and Future Directions}

There is now more or less incontrovertible evidence that, apart from their developmental effects on the CNS, thyroid hormones have major effects on the metabolic activity of the mature brain. Mood disorders are intimately associated with suboptimal thyroid function. Although comparatively less investigated, increasing evidence has shown that HPT axis dysfunction is relevant to the aetiopathogenesis, course, treatment, and outcome of bipolar disorder. Hypothyroidism either overt or more commonly subclinical appears to the commonest abnormality found among patients with bipolar disorder. It is also likely that the prevalence of thyroid dysfunction is greater in patients with rapid cycling and more refractory forms of the disorder. Lithium has potent anti-thyroid effects and can induce hypothyroidism among patients on this treatment; alternatively, it can exacerbate a preexisting hypothyroid state. Even minor perturbations of the HPT axis in the normal range have the potential to affect the outcome of bipolar disorder. Awareness of this fact is required among clinicians, and patients should be carefully monitored and managed for HPT axis dysfunction. Supplementation with high dose T4 can be considered in some patients, refractory to standard measures of treatment. Genetic, neuroimaging, and neurotransmitter studies are providing newer insights into the complex interactions between HPT function and bipolar disorder.

Although current research, especially preclinical, research has provided strong leads, the precise cellular and molecular mechanisms underlying the role of thyroid hormones in pathophysiology and treatment of mood disorders are still to be delineated. Future attempts need to fill this gap by focusing on translational studies, which can successfully extend preclinical findings to the clinical realm of bipolar disorder, in the true spirit of "bench-to-bedside" research. Additionally, the clinical component of future research needs to identify those patients with bipolar disorders who are most likely to benefit from therapeutic manipulations of the HPT axis, for example, by focusing on genetic markers. Together, 
these two strands of research can not only enhance our understanding of the thyroid-bipolar disorder connection, but also lead to more optimal ways of managing this potentially disabling condition.

\section{References}

[1] M. Bauer, T. Goetz, T. Glenn, and P. C. Whybrow, "The thyroid-brain interaction in thyroid disorders and mood disorders," Journal of Neuroendocrinology, vol. 20, no. 10, pp. 1101-1114, 2008.

[2] M. Bauer, A. Heinz, and P. C. Whybrow, "Thyroid hormones, serotonin and mood: of synergy and significance in the adult brain," Molecular Psychiatry, vol. 7, no. 2, pp. 140-156, 2002.

[3] V. Hendrick, L. Altshuler, and P. Whybrow, "Psychoneuroendocrinology of mood disorders: the hypothalamic-pituitarythyroid axis," Psychiatric Clinics of North America, vol. 21, no. 2, pp. 277-292, 1998.

[4] P. M. Yen, "Physiological and molecular basis of thyroid hormone action," Physiological Reviews, vol. 81, no. 3, pp. 1097-1142, 2001.

[5] M. Bauer and P. C. Whybrow, "Thyroid hormone, brain, and behaviour," in Hormones, Brain and Behavior, D. W. Pfaff, A. P. Arnold, A. M. Etgen, S. E. Fahrbach, and R. T. Rubin, Eds., pp. 238-264, Academic Press, New York, NY, USA, 2002.

[6] K. Boelaert and J. A. Franklyn, "Thyroid hormone in health and disease," Journal of Endocrinology, vol. 187, no. 1, pp. 1$15,2005$.

[7] T. Xu, "Characterizing thyroid-depression interactions: an interdisciplinary approach," Journal of Young Investigators, vol. 20, no. 10, pp. 1-9, 2010.

[8] R. Bunevičius and A. J. Prange, "Thyroid disease and mental disorders: cause and effect or only comorbidity?" Current Opinion in Psychiatry, vol. 23, no. 4, pp. 363-368, 2010.

[9] C. S.-N. Lee and B. Hutto, "Recognizing thyrotoxicosis in a patient with bipolar mania: a case report," Annals of General Psychiatry, vol. 7, article 3, 2008.

[10] J. Nath and R. Sagar, "Late-onset bipolar disorder due to hyperthyroidism," Acta Psychiatrica Scandinavica, vol. 104, no. 1, pp. 72-73, 2001.

[11] S. A. Checkley, "Thyrotoxicosis and the course of manicdepressive illness," British Journal of Psychiatry, vol. 133, no. 9, pp. 219-223, 1978.

[12] V. I. Reus, P. Gold, and R. Post, "Lithium-induced thyrotoxicosis," American Journal of Psychiatry, vol. 136, no. 5, pp. 724 $725,1979$.

[13] D. Bandyopadhyay and C. Nielsen, "Lithium-induced hyperthyroidism, thyrotoxicosis and mania: a case report," Quarterly Journal of Medicine. In Press.

[14] C. D. Carmaciu, C. S. Anderson, and C. A. Lawton, "Thyrotoxicosis after complete or partial lithium withdrawal in two patients with bipolar affective disorder," Bipolar Disorders, vol. 5, no. 5, pp. 381-384, 2003.

[15] M. A. C. Onuigbo, M. E. Cuffy-Hallam, and K. J. Wiley, "Painless thyroiditis: the rare phenomenon of lithiumassociated thyrotoxicosis," Hospital Physician, vol. 36, no. 9, pp. 48-50, 2000.

[16] K. K. Miller and G. H. Daniels, "Association between lithium use and thyrotoxicosis caused by silent thyroiditis," Clinical Endocrinology, vol. 55, no. 4, pp. 501-508, 2001.

[17] A. Sathya, R. Radhika, S. Mahadevan, and U. Sriram, "Mania as a presentation of primary hypothyroidism," Singapore Medical Journal, vol. 50, no. 2, pp. e65-e67, 2009.
[18] C. P. Stowell and J. W. Barnhill, "Acute mania in the setting of severe hypothyroidism," Psychosomatics, vol. 46, no. 3, pp. 259-261, 2005.

[19] A. M. Josephson and T. B. Mackenzie, "Thyroid-induced mania in hypothyroid patients," British Journal of Psychiatry, vol. 137, no. 3, pp. 222-228, 1980.

[20] D. L. Evans, S. K. Strawn, and J. J. Haggerty Jr., "Appearance of mania in drug-resistant bipolar depressed patients after treatment with L-triiodothyronine," Journal of Clinical Psychiatry, vol. 47, no. 10, pp. 521-522, 1986.

[21] A. F. Thomsen and L. V. Kessing, "Increased risk of hyperthyroidism among patients hospitalized with bipolar disorder," Bipolar Disorders, vol. 7, no. 4, pp. 351-357, 2005.

[22] A. F. Thomsen, T. K. Kvist, P. K. Andersen, and L. V. Kessing, "Increased risk of affective disorder following hospitalisation with hyperthyroidism-a register-based study," European Journal of Endocrinology, vol. 152, no. 4, pp. 535-543, 2005.

[23] A. F. Thomsen, T. K. Kvist, P. K. Andersen, and L. V. Kessing, "Increased risk of developing affective disorder in patients with hypothyroidism: a register-based study," Thyroid, vol. 15, no. 7, pp. 700-707, 2005.

[24] E. M. Stranges, R. L. Houchens, T. L. Mark et al., "Patients with bipolar disorder at higher risk for wide range of physical comorbidities," Thomson Reuters, 2009, http://home.thomsonhealthcare.com/research/treemaps.

[25] J. M. Azorin, A. Kaladjian, M. Adida et al., "Factors associated with rapid cycling in bipolar I manic patients: findings from a French national study," CNS Spectrums, vol. 13, no. 9, pp. 780-787, 2008.

[26] K. R. R. Krishnan, "Psychiatric and medical comorbidities of bipolar disorder," Psychosomatic Medicine, vol. 67, no. 1, pp. $1-8,2005$.

[27] R. S. McIntyre, J. Z. Konarski, J. K. Soczynska et al., "Medical comorbidity in bipolar disorder: implications for functional outcomes and health service utilization," Psychiatric Services, vol. 57, no. 8, pp. 1140-1144, 2006.

[28] A. M. Kilbourne, J. R. Cornelius, X. Han et al., "Burden of general medical conditions among individuals with bipolar disorder," Bipolar Disorders, vol. 6, no. 5, pp. 368-373, 2004.

[29] E. Szabadi, "Thyroid dysfunction and affective illness," British Medical Journal, vol. 302, no. 6782, pp. 923-924, 1991.

[30] B. Müller-Oerlinghausen, A. Berghöfer, and M. Bauer, "Bipolar disorder," The Lancet, vol. 359, no. 9302, pp. 241247, 2002.

[31] A. Ezzaher, F. Neffati, A. Mechri, W. Douki, L. Gaha, and M. F. Najjar, "Evaluation of thyroid function in bipolar patients," Clinical Chemistry and Laboratory Medicine, vol. 47, no. S1, article S371, 2009.

[32] A. Bocchetta and A. Loviselli, "Lithium treatment and thyroid abnormalities," Clinical Practice and Epidemiology in Mental Health, vol. 2, article 23, 2006.

[33] J. W. Mason, J. L. Kennedy, T. R. Kosten, and E. L. Giller Jr., "Serum thyroxine levels in schizophrenic and affective disorder diagnostic subgroups," Journal of Nervous and Mental Disease, vol. 177, no. 6, pp. 351-358, 1989.

[34] P. R. Joyce, "The prognostic significance of thyroid function in mania," Journal of Psychiatric Research, vol. 25, no. 1-2, pp. $1-6,1991$.

[35] S. T. H. Sokolov, S. P. Kutcher, and R. T. Joffe, "Basal thyroid indices in adolescent depression and bipolar disorder," Journal of the American Academy of Child and Adolescent Psychiatry, vol. 33, no. 4, pp. 469-475, 1994. 
[36] S. Lee, C. C. Chow, Y. K. Wing et al., "Thyroid function and psychiatric morbidity in patients with manic disorder receiving lithium therapy," Journal of Clinical Psychopharmacology, vol. 20, no. 2, pp. 204-209, 2000.

[37] S. Southwick, J. W. Mason, E. L. Giller Jr., and T. R. Kosten, "Serum thyroxine change and clinical recovery in psychiatric inpatients," Biological Psychiatry, vol. 25, no. 1, pp. 67-74, 1989.

[38] R. P. Roca, M. R. Blackman, M. B. Ackerley, S. M. Harman, and R. I. Gregerman, "Thyroid hormone elevations during acute psychiatric illness: relationship to severity and distinction from hyperthyroidism," Endocrine Research, vol. 16, no. 4, pp. 415-447, 1990.

[39] L. B. Marangell and A. M. Callahan, "Mood disorders and the thyroid axis," Current Opinion in Psychiatry, vol. 11, no. 1, pp. 67-70, 1998.

[40] P. T. Loosen, "The TRH-induced TSH response in psychiatric patients: a possible neuroendocrine marker," Psychoneuroendocrinology, vol. 10, no. 3, pp. 237-260, 1985.

[41] I. Extein, A. L. C. Pottash, M. S. Gold, and R. W. Cowdry, "Using the protirelin test to distinguish mania from schizophrenia," Archives of General Psychiatry, vol. 39, no. 1, pp. 77-81, 1982.

[42] N. Kiriike, Y. Izumiya, S. Nishiwaki, Y. Maeda, T. Nagata, and Y. Kawakita, "TRH test and DST in schizoaffective mania, mania, and schizophrenia," Biological Psychiatry, vol. 24, no. 4, pp. 415-422, 1988.

[43] P. Linkowski, H. Brauman, and J. Mendlewicz, "Thyrotrophin response to thyrotrophin-releasing hormone in unipolar and bipolar affective illness," Journal of Affective Disorders, vol. 3, no. 1, pp. 9-16, 1981.

[44] A. J. Rush, D. E. Giles, M. A. Schlesser et al., "Dexamethasone response, thyrotropin-releasing hormone stimulation, rapid eye movement latency, and subtypes of depression," Biological Psychiatry, vol. 41, no. 9, pp. 915-928, 1997.

[45] D. A. Sack, S. P. James, N. E. Rosenthal, and T. A. Wehr, "Deficient nocturnal surge of TSH secretion during sleep and sleep deprivation in rapid-cycling bipolar illness," Psychiatry Research, vol. 23, no. 2, pp. 179-191, 1988.

[46] J. K. Larsen, J. Faber, E. M. Christensen et al., "Relationship between mood and TSH response to TRH stimulation in bipolar affective disorder," Psychoneuroendocrinology, vol. 29, no. 7, pp. 917-924, 2004.

[47] P. T. Loosen, "The TRH stimulation test in psychiatric disorders: a review," in Handbook of Clinical Psvchoneuroendocrinology, C. B. Nemeroff and P.T. Loosen, Eds., pp. 336360, Guilford Press, New York, NY, USA, 1987.

[48] C. Kirkegaard and J. Faber, "The role of thyroid hormones in depression," European Journal of Endocrinology, vol. 138, no. 1, pp. 1-9, 1998.

[49] S. C. Bahls and G. A. De Carvalho, "The relation between thyroid function and depression: a review," Revista Brasileira de Psiquiatria, vol. 26, no. 1, pp. 41-49, 2004.

[50] L. Gyulai, M. Bauer, M. S. Bauer, F. García-España, A. Cnaan, and P. C. Whybrow, "Thyroid hypofunction in patients with rapid-cycling bipolar disorder after lithium challenge," Biological Psychiatry, vol. 53, no. 10, pp. 899-905, 2003.

[51] J. H. Lazarus, "The effects of lithium therapy on thyroid and thyrotropin-releasing hormone," Thyroid, vol. 8, no. 10, pp. 909-913, 1998.

[52] J. Valle, J. L. Ayuso-Gutierrez, A. Abril, and J. L. AyusoMateos, "Evaluation of thyroid function in lithium-naive bipolar patients," European Psychiatry, vol. 14, no. 6, pp. 341345, 1999.
[53] R. W. Kupka, W. A. Nolen, R. M. Post et al., "High rate of autoimmune thyroiditis in bipolar disorder: lack of association with lithium exposure," Biological Psychiatry, vol. 51, no. 4, pp. 305-311, 2002.

[54] M. Ahmed and R. Morriss, "Assessment and management of rapid-cycling bipolar affective disorder," Advances in Psychiatric Treatment, vol. 3, no. 6, pp. 367-373, 1997.

[55] N. Kilzieh and H. S. Akiskal, "Rapid-cycling bipolar disorder: an overview of research and clinical experience," Psychiatric Clinics of North America, vol. 22, no. 3, pp. 585-607, 1999.

[56] C. D. Schneck, "Treatment of rapid-cycling bipolar disorder," Journal of Clinical Psychiatry, vol. 67, no. 11, supplement, pp. 22-27, 2006.

[57] T. A. Wehr and F. K. Goodwin, "Rapid cycling in manicdepressives induced by tricyclic antidepressants," Archives of General Psychiatry, vol. 36, no. 5, pp. 555-559, 1979.

[58] R. W. Cowdry, T. A. Wehr, A. P. Zis, and F. K. Goodwin, "Thyroid abnormalities associated with rapid-cycling bipolar illness," Archives of General Psychiatry, vol. 40, no. 4, pp. 414420, 1983.

[59] H. R. Khouzam, V. G. Bhat, J. Boyer, and W. Hardy, "Rapid cycling in a patient with bipolar mood disorder secondary to Graves' disease," American Journal of Psychiatry, vol. 148, no. 9, pp. 1272-1273, 1991.

[60] G. J. O'Shanick and E. H. Ellinwood, "Persistent elevation of thyroid-stimulating hormone in women with bipolar affective disorder," American Journal of Psychiatry, vol. 139, no. 4, pp. 513-514, 1982.

[61] M. S. Bauer, P. C. Whybrow, and A. Winokur, "Rapid cycling bipolar affective disorder. I. Association with grade I hypothyroidism," Archives of General Psychiatry, vol. 47, no. 5, pp. 427-432, 1990.

[62] M. Kusalic, "Grade II and grade III hypothyroidism in RapidCycling bipolar patients," Neuropsychobiology, vol. 25, no. 4, pp. 177-181, 1992.

[63] H. A. P. C. Oomen, A. J. M. Schipperijn, and H. A. Drexhage, "The prevalence of affective disorder and in particular of a rapid cycling of bipolar disorder in patients with abnormal thyroid function tests," Clinical Endocrinology, vol. 45, no. 2, pp. 215-223, 1996.

[64] L. Bartalena, L. Pellegrini, M. Meschi et al., "Evaluation of thyroid function in patients with rapid-cycling and nonrapid-cycling bipolar disorder," Psychiatry Research, vol. 34, no. 1, pp. 13-17, 1990.

[65] R. T. Joffe, S. Kutcher, and C. MacDonald, "Thyroid function and bipolar affective disorder," Psychiatry Research, vol. 25, no. 2, pp. 117-121, 1988.

[66] T. A. Wehr, D. A. Sack, N. E. Rosenthal, and R. W. Cowdry, "Rapid cycling affective disorder: contributing factors and treatment responses in 51 patients," American Journal of Psychiatry, vol. 145, no. 2, pp. 179-184, 1988.

[67] M. Maj, L. Magliano, R. Pirozzi, C. Marasco, and M. Guarneri, "Validity of rapid cycling as a course specifier for bipolar disorder," American Journal of Psychiatry, vol. 151, no. 7, pp. 1015-1019, 1994.

[68] R. M. Post, K. G. Kramlinger, R. T. Joffe et al., "Rapid cycling bipolar affective disorder: lack of relation to hypothyroidism," Psychiatry Research, vol. 72, no. 1, pp. 1-7, 1997.

[69] P. Brieger, "Do comorbidity studies support the idea that mixed states and rapid-cycling forms are distinct categories of bipolar disorders?" Clinical Neuropsychiatry, vol. 1, no. 3, pp. 175-181, 2004. 
[70] J. T. Cho, S. Bone, and D. L. Dunner, "The effect of lithium treatment on thyroid function in patients with primary affective disorder," American Journal of Psychiatry, vol. 136, no. 1, pp. 115-116, 1979.

[71] C. A. Zarate, M. Tohen, and S. B. Zarate, "Thyroid function tests in first-episode bipolar disorder manic and mixed types," Biological Psychiatry, vol. 42, no. 4, pp. 302-304, 1997.

[72] K. D. Chang, P. E. Keck, S. P. Stanton, S. L. McElroy, S. M. Strakowski, and T. D. Geracioti, "Differences in thyroid function between bipolar manic and mixed states," Biological Psychiatry, vol. 43, no. 10, pp. 730-733, 1998.

[73] J. J. Haggerty Jr., D. L. Evans, R. N. Golden, C. A. Pedersen, J. S. Simon, and C. B. Nemeroff, "The presence of antithyroid antibodies in patients with affective and nonaffective psychiatric disorders," Biological Psychiatry, vol. 27, no. 1, pp. 5160, 1990.

[74] J. J. Haggerty Jr., S. G. Silva, M. Marquardt et al., "Prevalence of antithyroid antibodies in mood disorders," Depression and Anxiety, vol. 5, no. 2, pp. 91-96, 1997.

[75] R. T. Joffe, L. T. Young, R. G. Cooke, and J. Robb, "The thyroid and mixed affective states," Acta Psychiatrica Scandinavica, vol. 90, no. 2, pp. 131-132, 1994.

[76] F. Cassidy, E. P. Ahearn, and B. J. Carroll, "Thyroid function in mixed and pure manic episodes," Bipolar Disorders, vol. 4, no. 6, pp. 393-397, 2002.

[77] R. Salata and I. Klein, "Effects of lithium on the endocrine system: a review," Journal of Laboratory and Clinical Medicine, vol. 110, no. 2, pp. 130-136, 1987.

[78] C. Livingstone and H. Rampes, "Lithium: a review of its metabolic adverse effects," Journal of Psychopharmacology, vol. 20, no. 3, pp. 347-355, 2006.

[79] T. Terao, T. Oga, S. Nozaki et al., "Possible inhibitory effect of lithium on peripheral conversion of thyroxine to triiodothyronine: a prospective study," International Clinical Psychopharmacology, vol. 10, no. 2, pp. 103-105, 1995.

[80] J. H. Lazarus, "Lithium and thyroid," Best Practice and Research: Clinical Endocrinology and Metabolism, vol. 23, no. 6, pp. 723-733, 2009.

[81] C. G. Hahn, A. C. Pawlyk, P. C. Whybrow, and S. M. TejaniButt, "Differential expression of thyroid hormone receptor isoforms by thyroid hormone and lithium in rat GH3 and B103 cells," Biological Psychiatry, vol. 45, no. 8, pp. 10041012, 1999.

[82] G. Kirov, "Thyroid disorders in lithium-treated patients," Journal of Affective Disorders, vol. 50, no. 1, pp. 33-40, 1998.

[83] A. M. Johnston and J. M. Eagles, "Lithium-associated clinical hypothyroidism. Prevalence and risk factors," British Journal of Psychiatry, vol. 175, pp. 336-339, 1999.

[84] C. H. Emerson, W. L. Dysno, and R. D. Utiger, "Serum thyrotropin and thyroxine concentrations in patients recieving lithium carbonate," Journal of Clinical Endocrinology and Metabolism, vol. 36, no. 2, pp. 338-346, 1973.

[85] M. A. Frye, K. D. Denicoff, A. L. Bryan et al., "Association between lower serum free T4 and greater mood instability and depression in lithium-maintained bipolar patients," American Journal of Psychiatry, vol. 156, no. 12, pp. 19091914, 1999.

[86] S.-A. Ahmadi-Abhari, P. Ghaeli, F. Fahimi et al., "Risk factors of thyroid abnormalities in bipolar patients receiving lithium: a case control study," BMC Psychiatry, vol. 3, article 4, 2003.

[87] N. Ozpoyraz, L. Tamam, and E. Kulan, "Thyroid abnormalities in lithium-treated patients," Advances in Therapy, vol. 19, no. 4, pp. 176-184, 2002.
[88] J. Kleiner, L. Altshuler, V. Hendrick, and J. M. Hershman, "Lithium-induced subclinical hypothyroidism: review of the literature and guidelines for treatment," Journal of Clinical Psychiatry, vol. 60, no. 4, pp. 249-255, 1999.

[89] J. H. Lazarus, R. John, and E. H. Bennie, "Lithium therapy and thyroid function: a long-term study," Psychological Medicine, vol. 11, no. 1, pp. 85-92, 1981.

[90] U. Schiemann and K. Hengst, "Thyroid echogenicity in manic-depressive patients receiving lithium therapy," Journal of Affective Disorders, vol. 70, no. 1, pp. 85-90, 2002.

[91] G. Lindstedt, L. A. Nilsson, and J. Walinder, "On the prevalence, diagnosis and management of lithium induced hypothyroidism in psychiatric patients," British Journal of Psychiatry, vol. 130, no. 5, pp. 452-458, 1977.

[92] P. Deniker, A. Eyquem, and R. Bernheim, "Thyroid autoantibody levels during lithium therapy," Neuropsychobiology, vol. 4, no. 5, pp. 270-275, 1978.

[93] L. Smigan, A. Wahlin, L. Jacobsson, and L. Von Knorring, "Lithium therapy and thyroid function tests. A prospective study," Neuropsychobiology, vol. 11, no. 1, pp. 39-43, 1984.

[94] J. R. Calabrese, A. D. Gulledge, and K. Hahn, "Autoimmune thyroiditis in manic-depressive patients treated with lithium," American Journal of Psychiatry, vol. 142, no. 11, pp. 1318-1321, 1985.

[95] M. C. Leroy, A. Villeneuve, and C. Lajeunesse, "Lithium and antithyroid antibodies," American Journal of Psychiatry, vol. 145 , no. 4 , p. $534,1988$.

[96] A. Bocchetta, F. Bernardi, M. Pedditzi et al., "Thyroid abnormalities during lithium treatment," Acta Psychiatrica Scandinavica, vol. 83, no. 3, pp. 193-198, 1991.

[97] J. Bolo-Deoku, H. Wilcox, B. Harris et al., "Thyroid dysfunction and affective illness," British Medical Journal, vol. 302, no. 6789 , p. $1403,1991$.

[98] S. Lee, C. C. Chow, Y. K. Wing, and C. C. Shek, "Thyroid abnormalities during chronic lithium treatment in Hong Kong Chinese: a controlled study," Journal of Affective Disorders, vol. 26, no. 3, pp. 173-178, 1992.

[99] M. Aliasgharpour, M. Abbassi, H. Shafaroodi, and F. Razi, "Subclinical hypothyroidism in lithium-treated psychiatric patients in Tehran, Islamic Republic of Iran," Eastern Mediterranean Health Journal, vol. 11, no. 3, pp. 329-333, 2005.

[100] S. Ozsoy, E. Mavili, M. Aydin, T. Turan, and E. Esel, "Ultrasonically determined thyroid volume and thyroid functions in lithium-naïve and lithium-treated patients with bipolar disorder: a cross-sectional and longitudinal study," Human Psychopharmacology, vol. 25, no. 2, pp. 174-178, 2010.

[101] J. H. Lazarus, A. M. McGregor, and M. Ludgate, "Effect of lithium carbonate therapy on thyroid immune status in manic depressive patients: a prospective study," Journal of Affective Disorders, vol. 11, no. 2, pp. 155-160, 1986.

[102] B. Spivak, M. Radwan, P. Bartur, R. Mester, and A. Weizman, "Antinuclear autoantibodies in relation to bipolar affective disorder and lithium therapy," European Psychiatry, vol. 11, no. 1, pp. 50-52, 1996.

[103] M. Hornig, J. D. Amsterdam, M. Kamoun, and D. B. P. Goodman, "Autoantibody disturbances in affective disorders: a function of age and gender?" Journal of Affective Disorders, vol. 55, no. 1, pp. 29-37, 1999.

[104] C. Baethge, H. Blumentritt, A. Berghöfer et al., "Longterm lithium treatment and thyroid antibodies: a controlled study," Journal of Psychiatry and Neuroscience, vol. 30, no. 6, pp. 423-427, 2005. 
[105] R. Wilson, J. H. McKillop, G. T. Crocket et al., "The effect of lithium therapy on parameters thought to be involved in the development of autoimmune thyroid disease," Clinical Endocrinology, vol. 34, no. 5, pp. 357-361, 1991.

[106] M. H. Rapaportt, "Immune parameters in euthymic bipolar patients and normal volunteers," Journal of Affective Disorders, vol. 32, no. 3, pp. 149-156, 1994.

[107] N. Ferrier, S. P. Tyrer, and A. J. Bell, "Lithium therapy," Advances in Psychiatric Treatment, vol. 1, no. 4, pp. 102-110, 1995.

[108] R. T. Joffe, "How should lithium-induced thyroid dysfunction be managed in patients with bipolar disorder?" Journal of Psychiatry and Neuroscience, vol. 27, no. 5, p. 392, 2002.

[109] O. Abulseoud, N. Sane, A. Cozzolino et al., "Free T4 index and clinical outcome in patients with depression," Journal of Affective Disorders, vol. 100, no. 1-3, pp. 271-277, 2007.

[110] D. P. Cole, M. E. Thase, A. G. Mallinger et al., "Slower treatment response in bipolar depression predicted by lower pretreatment thyroid function," American Journal of Psychiatry, vol. 159, no. 1, pp. 116-121, 2002.

[111] A. Baumgartner, M. von Stuckrada, B. Müller-Oerlinghausena, K.-J. Gräfb, and I. Kürtenb, "The hypothalamicpituitary-thyroid axis in patients maintained on lithium prophylaxis for years: high triiodothyronine serum concentrations are correlated to the prophylactic efficacy," Journal of Affective Disorders, vol. 34, no. 3, pp. 211-218, 1995.

[112] J. A. Hatterer, J. H. Kocsis, and P. E. Stokes, "Thyroid function in patients maintained on lithium," Psychiatry Research, vol. 26, no. 3, pp. 249-257, 1988.

[113] M. A. Frye, L. Yatham, T. A. Ketter et al., "Depressive relapse during lithium treatment associated with increased serum thyroid-stimulating hormone: results from two placebocontrolled bipolar i maintenance studies," Acta Psychiatrica Scandinavica, vol. 120, no. 1, pp. 10-13, 2009.

[114] H. C. Stancer and E. Persad, "Treatment of intractable rapid-cycling manic-depressive disorder with levothyroxine," Archives of General Psychiatry, vol. 39, no. 3, pp. 311-312, 1982.

[115] M. S. Bauer and P. C. Whybrow, "The effect of changing thyroid function on cyclic affective illness in a human subject," American Journal of Psychiatry, vol. 143, no. 5, pp. 633-636, 1986.

[116] M. S. Bauer and P. C. Whybrow, "Rapid cycling bipolar affective disorder. II. Treatment of refractory rapid cycling with high-dose levothyroxine: a preliminary study," Archives of General Psychiatry, vol. 47, no. 5, pp. 435-440, 1990.

[117] A. Baumgartner, M. Bauer, and R. Hellweg, "Treatment of intractable non-rapid cycling dipolar affective disorder with high-dose thyroxine: an open clinical trial," Neuropsychopharmacology, vol. 10, no. 3, pp. 183-189, 1994.

[118] M. Bauer, A. Berghöfer, T. Bschor et al., "Supraphysiological doses of L-Thyroxine in the maintenance treatment of prophylaxis-resistant affective disorders," Neuropsychopharmacology, vol. 27, no. 4, pp. 620-628, 2002.

[119] M. Bauer, S. Priebe, A. Berghöfer, T. Bschor, U. Kiesslinger, and P. C. Whybrow, "Subjective response to and tolerability of long-term supraphysiological doses of levothyroxine in refractory mood disorders," Journal of Affective Disorders, vol. 64 , no. 1, pp. 35-42, 2001.

[120] L. Gyulai, J. Jaggi, M. S. Bauer et al., "Bone mineral density and L-thyroxine treatment in rapidly cycling bipolar disorder," Biological Psychiatry, vol. 41, no. 4, pp. 503-506, 1997.
[121] L. Gyulai, M. Bauer, F. Garcia-Espana et al., "Bone mineral density in pre-and post-menopausal women with affective disorder treated with long-term L-thyroxine augmentation," Journal of Affective Disorders, vol. 66, no. 2-3, pp. 185-191, 2001.

[122] M. Bauer, L. Fairbanks, A. Berghöfer et al., "Bone mineral density during maintenance treatment with supraphysiological doses of levothyroxine in affective disorders: a longitudinal study," Journal of Affective Disorders, vol. 83, no. 2-3, pp. 183-190, 2004.

[123] M. Bauer, E. D. London, N. Rasgon et al., "Supraphysiological doses of levothyroxine alter regional cerebral metabolism and improve mood in bipolar depression," Molecular Psychiatry, vol. 10, no. 5, pp. 456-469, 2005.

[124] M. Bauer, R. Hellweg, K. J. Gräf, and A. Baumgartner, "Treatment of refractory depression with high-dose thyroxine," Neuropsychopharmacology, vol. 18, no. 6, pp. 444-455, 1998.

[125] M. Bauer, R. Hellweg, K. J. Graf, and A. Baumgartner, "Treatment of therapy-resistant depression with adjunctive high-dose thyroxine," Biological Psychiatry, vol. 42, no. 1, supplement, p. 258, 1997.

[126] D. Łojko and J. K. Rybakowski, "l-thyroxine augmentation of serotonergic antidepressants in female patients with refractory depression," Journal of Affective Disorders, vol. 103, no. 1-3, pp. 253-256, 2007.

[127] T. Kelly and D. Z. Lieberman, "The use of triiodothyronine as an augmentation agent in treatment-resistant bipolar II and bipolar disorder NOS," Journal of Affective Disorders, vol. 116, no. 3, pp. 222-226, 2009.

[128] M. A. H. Rot, S. J. Mathew, and D. S. Charney, "Neurobiological mechanisms in major depressive disorder," CMAJ, vol. 180, no. 3, pp. 305-313, 2009.

[129] D. J. Diehl and S. Gershon, "The role of dopamine in mood disorders," Comprehensive Psychiatry, vol. 33, no. 2, pp. 115120, 1992.

[130] P. Brambilla, J. Perez, F. Barale, G. Schettini, and J. C. Soares, "GABAergic dysfunction in mood disorders," Molecular Psychiatry, vol. 8, no. 8, pp. 721-737, 2003.

[131] R. V. Weatherman, "A triple play for thyroid hormone," ACS Chemical Biology, vol. 2, no. 6, pp. 377-379, 2007.

[132] C. B. Rozanov and M. B. Dratman, "Immunohistochemical mapping of brain triiodothyronine reveals prominent localization in central noradrenergic systems," Neuroscience, vol. 74, no. 3, pp. 897-915, 1996.

[133] S. C. Wiens and V. L. Trudeau, "Thyroid hormone and $\gamma$ aminobutyric acid (GABA) interactions in neuroendocrine systems," Comparative Biochemistry and Physiology, vol. 144, no. 3, pp. 332-344, 2006.

[134] M. J. Abrahamson and R. P. Millar, "Regulation of thyrotrophin secretion," South African Medical Journal, vol. 70, no. 8, pp. 476-478, 1986.

[135] G. A. Mason, J. C. Garbutt, and A. J. Prange Jr., "Thyrotropin-releasing hormone. Focus on basic neurobiology," in Psychopharmacology: The Fourth Generation of Progress, F. E. Bloom and D. J. Kupfer, Eds., pp. 493-503, Raven Press, New York, NY, USA, 1995.

[136] J. P. Bilezikian and J. N. Loeb, "The influence of hyperthyroidism and hypothyroidism on alpha- and beta-adrenergic receptor systems and adrenergic responsiveness," Endocrine Reviews, vol. 4, no. 4, pp. 378-388, 1983.

[137] J. R. Strawn, N. N. Ekhator, B. B. D'Souza, and T. D. Geracioti, "Pituitary-thyroid state correlates with central dopaminergic and serotonergic activity in healthy humans," Neuropsychobiology, vol. 49, no. 2, pp. 84-87, 2004. 
[138] O. M. Ahmed, S. M. Abd El-Tawab, and R. G. Ahmed, "Effects of experimentally induced maternal hypothyroidism and hyperthyroidism on the development of rat offspring: I. The development of the thyroid hormonesneurotransmitters and adenosinergic system interactions," International Journal of Developmental Neuroscience, vol. 28, no. 6, pp. 437-454, 2010.

[139] M. B. Dratman and J. T. Gordon, "Thyroid hormones as neurotransmitters," Thyroid, vol. 6, no. 6, pp. 639-647, 1996.

[140] J. Manzano, M. Cuadrado, B. Morte, and J. Bernal, "Influence of thyroid hormone and thyroid hormone receptors in the generation of cerebellar $\gamma$-aminobutyric acid-ergic interneurons from precursor cells," Endocrinology, vol. 148, no. 12, pp. 5746-5751, 2007.

[141] S. Westerholz, A. D. de Lima, and T. Voigt, "Regulation of early spontaneous network activity and GABAergic neurons development by thyroid hormone," Neuroscience, vol. 168, no. 2, pp. 573-589, 2010.

[142] P. C. Whybrow and A. J. Prange, "A hypothesis of thyroidcatecholamine-receptor interaction. Its relevance to affective illness," Archives of General Psychiatry, vol. 38, no. 1, pp. 106$113,1981$.

[143] M. Bauer, D. H. S. Silverman, F. Schlagenhauf et al., "Brain glucose metabolism in hypothyroidism: a positron emission tomography study before and after thyroid hormone replacement therapy," Journal of Clinical Endocrinology and Metabolism, vol. 94, no. 8, pp. 2922-2929, 2009.

[144] M. F. Schreckenberger, U. T. Egle, S. Drecker et al., "Positron emission tomography reveals correlations between brain metabolism and mood changes in hyperthyroidism," Journal of Clinical Endocrinology and Metabolism, vol. 91, no. 12, pp. 4786-4791, 2006.

[145] L. B. Marangell, T. A. Ketter, M. S. George et al., "Inverse relationship of peripheral thyrotropin-stimulating hormone levels to brain activity in mood disorders," American Journal of Psychiatry, vol. 154, no. 2, pp. 224-230, 1997.

[146] M. Piga, A. Serra, L. Deiana et al., "Brain perfusion abnormalities in patients with euthyroid autoimmune thyroiditis," European Journal of Nuclear Medicine and Molecular Imaging, vol. 31, no. 12, pp. 1639-1644, 2004.

[147] G. Zettinig, S. Asenbaum, B. J. Fueger et al., "Increased prevalence of sublinical brain perfusion abnormalities in patients with autoimmune thyroiditis: evidence of Hashimoto's encephalitis?" Clinical Endocrinology, vol. 59, no. 5, pp. 637643, 2003.

[148] A. Bocchetta, G. Tamburini, P. Cavolina, A. Serra, A. Loviselli, and M. Piga, "Affective psychosis, Hashimoto's thyroiditis, and brain perfusion abnormalities: case report," Clinical Practice and Epidemiology in Mental Health, vol. 3, article 31, 2007.

[149] R. Vonk, A. C. van der Schot, R. S. Kahn, W. A. Nolen, and H. A. Drexhage, "Is autoimmune thyroiditis part of the genetic vulnerability (or an Endophenotype) for bipolar disorder?" Biological Psychiatry, vol. 62, no. 2, pp. 135-140, 2007.

[150] M. H. J. Hillegers, C. G. Reichart, M. Wals et al., "Signs of a higher prevalence of autoimmune thyroiditis in female offspring of bipolar parents," European Neuropsychopharmacology, vol. 17, no. 6-7, pp. 394-399, 2007.

[151] M. Holtmann, E. Duketis, K. Goth, L. Poustka, and S. Boelte, "Severe affective and behavioral dysregulation in youth is associated with increased serum TSH," Journal of Affective Disorders, vol. 121, no. 1-2, pp. 184-188, 2010.
[152] B. He, J. Li, G. Wang et al., "Association of genetic polymorphisms in the type II deiodinase gene with bipolar disorder in a subset of Chinese population," Progress in NeuroPsychopharmacology and Biological Psychiatry, vol. 33, no. 6, pp. 986-990, 2009.

[153] D. Diez, C. Grijota-Martinez, P. Agretti et al., "Thyroid hormone action in the adult brain: gene expression profiling of the effects of single and multiple doses of triiodo-Lthyronine in the rat striatum," Endocrinology, vol. 149, no. 8, pp. 3989-4000, 2008.

[154] A. McQuillin, M. Rizig, and H. M. D. Gurling, "A microarray gene expression study of the molecular pharmacology of lithium carbonate on mouse brain mRNA to understand the neurobiology of mood stabilization and treatment of bipolar affective disorder," Pharmacogenetics and Genomics, vol. 17, no. 8, pp. 605-617, 2007. 


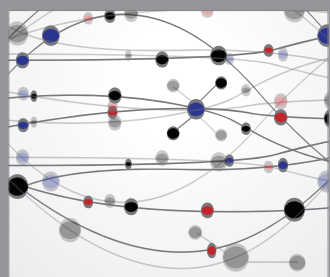

The Scientific World Journal
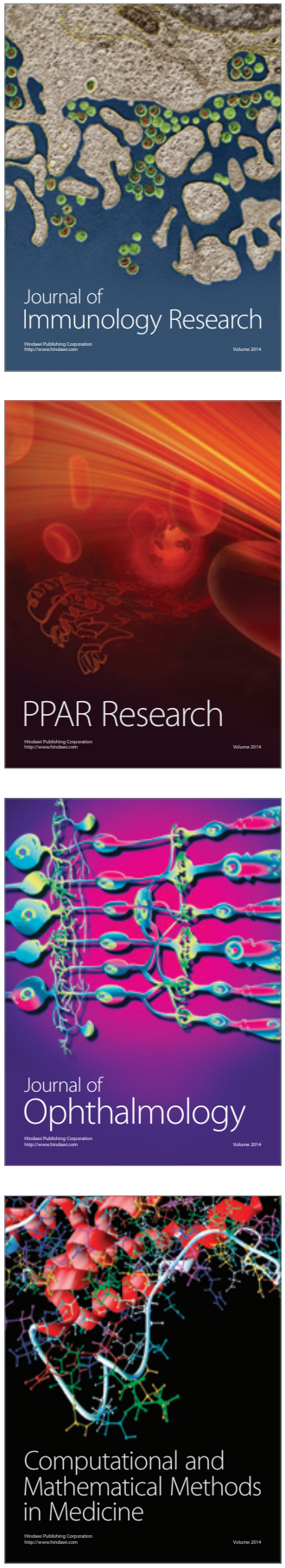

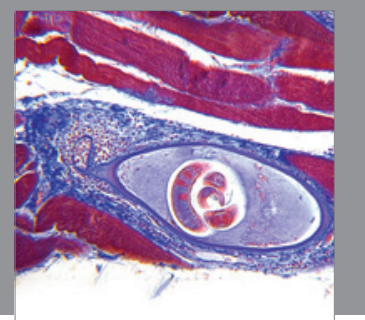

Gastroenterology

Research and Practice
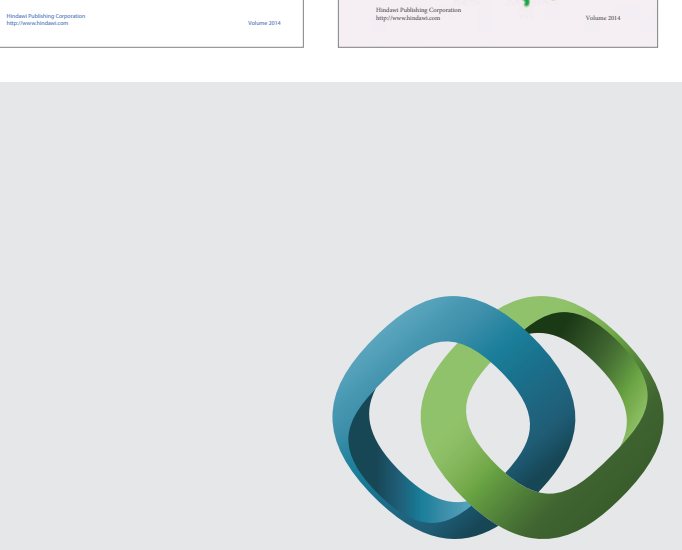

\section{Hindawi}

Submit your manuscripts at

http://www.hindawi.com
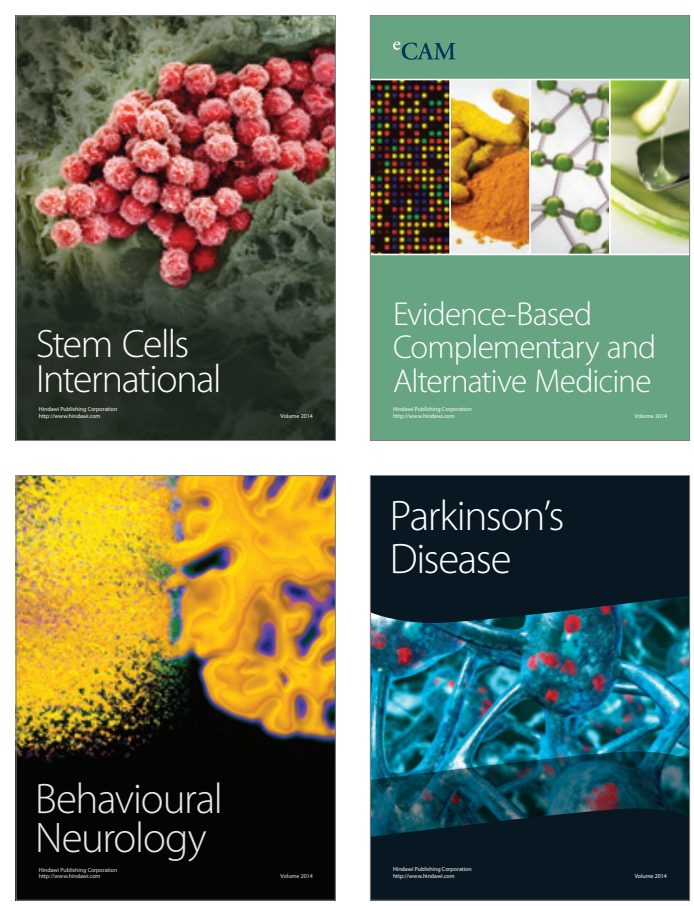

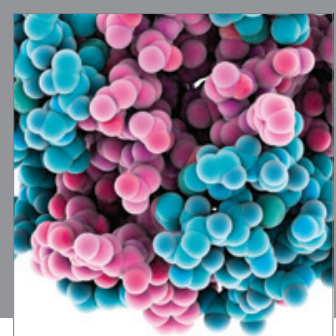

Journal of
Diabetes Research

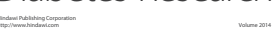

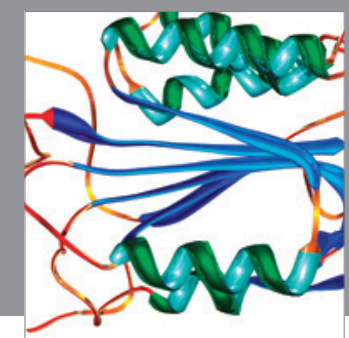

Disease Markers
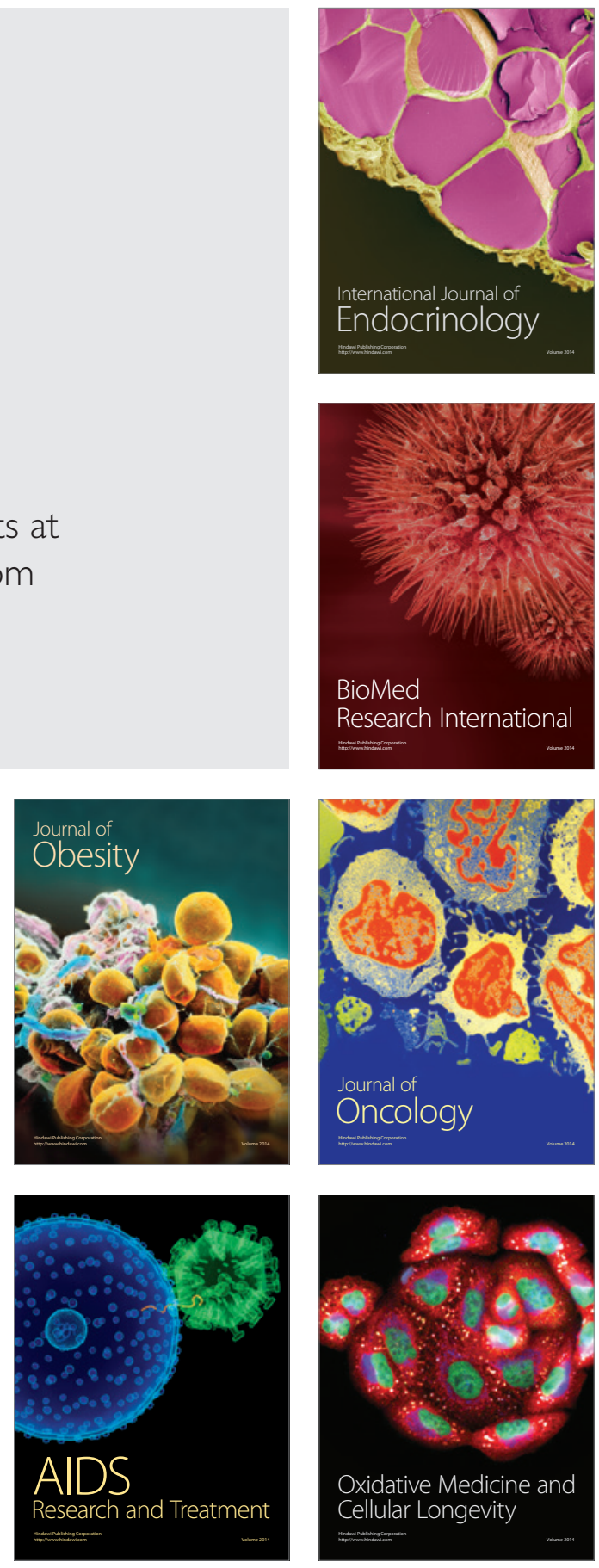